\title{
Entre mercado financiero y economía: la deuda pública en el Estado de Milán bajo los Austrias*
}

\author{
Giuseppe De Luca \\ Università degli Studi di Milano
}

RESUMEN: A partir de los años 40 del siglo XVI, el Ducado de Milán afrontó el problema de la financiación estatal a largo plazo sustituyendo progresivamente el mecanismo de los préstamos forzosos por la emisión directa de títulos de deuda pública, libremente suscritos, garantizados por un determinado ingreso fiscal destinado al pago de los intereses. Si el gobierno del ducado se vio empujado hacia esta dirección por el enorme desajuste de sus cuentas, el notable crecimiento de esta nueva forma de financiación, se concretó gracias a la buena acogida que tuvo por parte de una vasta pluralidad de sujetos, poseedores de fondos, que encontraron esta inversión acorde con sus propias exigencias. La generalización de la deuda pública y su exponencial incremento no parecen haberse traducido en un estéril drenaje de riqueza privada hacia objetivos bélicos y ni siquiera haber tenido efectos distorsionadores sobre la evolución de la economía real. Con la utilización de documentación proveniente del Archivio di Stato di Milano, del Archivo General de Simancas, de la Biblioteca Nazionale Braidense y del Archivio Storico della Camera di Commercio di Milano, para el caso lombardo se puede demostrar que esta forma de endeudamiento público a largo plazo, actuando en una situación de expansión monetaria, no des-

Traducción del texto italiano al español por Dra. Elena María García Guerra. Este artículo forma parte de las actividades adscritas al proyecto «Conseguir y conservar la riqueza en la España del siglo XVII: interacción entre teoría y práctica». Ministerio de Ciencia e Innovación. HAR2009-11939. IP: Dra. Elena María García Guerra.

* Archivos citados: Archivio di Stato di Milano: ASMI; Archivio Storico della Camera di Commercio di Milano: ASCCMI; Archivio Visconti di Modrone, Università Cattolica, Milano: AVDMI; Archivo General de Simancas: AGS; Archivo Histórico de Protocolos de Madrid: AHPM; Biblioteca Nazionale Braidense, Milano: BNB; Bibliothèque Nationale de France: BNF. 
plazó las inversiones productivas, haciendo disminuir su flujo o encareciéndolas. Por el contrario, produjo un efecto prociclico tanto durante la fase expansiva entre la segunda mitad del siglo XVI y 1620 como en la reorganización económica que tuvo lugar después.

\title{
Palabras Clave: Ducado de Milán; Edad Moderna; Deuda pública; Fiscalidad; Economía real; Estabilidad política.
}

\section{Between Financial Market and Economy: The Public Debt in Milan during the Habsburg Period}

\begin{abstract}
The State of Milan began to develop an efficient Public Debt system which replaced the forced loans previously issued by the capital of the Duchy, to the Crown since the middle decades of the sixteenth century. The new system was seen as a safe and sound investment bonds buyeurs and it enjoyed a warm welcome. The progressive rise of the Milanese Public Debt does not seem to have damaged the local real economy. In fact, an analysis based sources enable us to suggest that the expansion of a long term public debt founded on revenues obtained from taxes had clear pro-cycle effects on the economy of the Duchy, fostering the economic expansion in the second half of the sixteenth century and strengthening the economic reorganization followed after 1620.
\end{abstract}

KeY WORDS: Duchy of Milan; Early Modern Age; Public Debt; Taxation; Economy; Political Stability.

A partir de los años 40 del siglo XVI, al igual que en otros estados de la península italiana y de otras naciones, el Ducado de Milán afrontó el problema de la financiación estatal a largo plazo introduciendo innovaciones que potenciaron la recogida de dinero y unieron de manera cada vez más ramificada y profunda, la estructura y la gestión del poder político al capital financiero y a los recursos locales.

Se trató de la progresiva sustitución del mecanismo de los préstamos forzosos (que no desaparecieron del todo) por la emisión directa de títulos sobre el mercado (las rentas enajenadas), libremente suscritos, garantizados por un determinado ingreso fiscal destinado al pago de los intereses, carentes de plazos prefijados para la restitución del capital, comercializables, transferibles por vía hereditaria y exentos de secuestros o tasas. Si el gobierno del ducado se vio empujado hacia esta dirección por el enorme desajuste de sus cuentas, nacido de las necesidades bélicas y de los límites del propio sistema fiscal (ver Párrafo I), el notable crecimiento de esta nueva forma de financiación, se concretó gracias a la buena acogida que tuvo por parte de una vasta pluralidad de sujetos, poseedores de fondos, que encontraron esta inversión acorde con sus propias exigencias (ver Párrafo II). Durante algunos periodos pareció instaurarse un auténtico mecanismo push-pull, que dio lugar a que la respuesta 
de los compradores fuese extraordinariamente rápida; en 1559 la venta de 600.000 liras de rentas al 12\% realizada en la lonja de los mercaderes de Milán, se agotó en sólo diez días'

$\mathrm{Al}$ mismo tiempo, la generalización de este genotipo de deuda pública y su tumultuoso incremento no parecen haberse traducido en un estéril drenaje de riqueza privada hacia objetivos bélicos y ni siquiera haber tenido efectos distorsionadores sobre la evolución de la economía real. Además de constituir un medio de redistribución de la renta y de consolidación de los patrimonios, para el caso lombardo se puede demostrar que esta forma de endeudamiento público a largo plazo, actuando en una situación de expansión monetaria, no desplazó las inversiones productivas, haciendo disminuir su flujo o encareciéndolas. Por el contrario, produjo un efecto prociclico tanto durante la fase expansiva entre la segunda mitad del siglo XVI y 1620 como en la reorganización económica que tuvo lugar después; durante la primera fase, los títulos públicos aumentaron las posibilidades de financiación privada, actuando como matriz de crédito (es decir, como garantía para el establecimiento de contratos de préstamo a largo plazo como los censos consignativos) para mercaderes y empresarios; durante el segundo período citado, cuando el equilibrio entre los sectores agrícola y mercantil parecía menos dinámico, la deuda permitió al Estado mantener la demanda pública y a los grupos dirigentes — que obtenían de las rentas enajenadas un beneficio al abrigo de la inflación y de la fiscalidad- mantener un notable consumo destinado a la ostentación (en ropa, obras de arte, palacios pero también en casas de campo que eran rentables haciendas agrícolas).

Desde otro punto de vista, los inversores en rentas y los arrendadores que las recaudaban aparecen como los protagonistas de un proceso de acumulación «cultural» que está en el origen de un recorrido secular de modernización capitalista; estos sujetos se perfilan como los portadores de comportamientos individuales menos ligados a lógicas distributivas y más cercanos a estrategias de inversión basadas en una racionalidad «económica» y que tenían en cuenta la valoración del riesgo (ver Párrafo III).

Por otro lado, las inversiones en deuda pública constituyeron un instrumento de implicación y de integración de los suscriptores en las estrategias «centrales» del Ducado y desempeñaron un papel fundamental en la conservación de la estabilidad política en este dominio durante el siglo XVII (ver Párrafo IV).

I. Ya desde la época de Francesco Sforza, los duques milaneses habían recurrido muchas veces a la venta, fundamentalmente forzosa, de impuestos estatales a cambio de la anticipación de una suma igual al valor capitalizado,

1 ASMI, Finanze reddituari, cart. 1, «Per la nota de reddituari, 1559». En Venecia, en 1639, la colocación de una serie de depósitos al 5\% se realizó en sólo seis días, PEZZOLO, (Nápoles, 1995): 309. 
con un determinado tipo de interés (entre el 5, 7 y 10\%), del rendimiento anual del tributo sobre el que la autoridad se reservaba el derecho de redención. Junto a los territorios del ducado, en 1535 los españoles heredaron este tipo de deuda pública cuyo capital nominal alcanzaba 2.394.041 liras y cuyo pago de intereses absorvía el $11,3 \%$ del conjunto de las rentas previstas, que para el año 1536 alcanzaría 1.208.364².

Pero será a partir de este momento, cuando la enajenación de las rentas del Estado milanés pierde el carácter de suscripción obligatoria y se convierte en la base de una deuda consolidada destinada a asumir muy diferente dimensión. La estrategia universalista de Carlos V exigía una cadencia y un papel diferente, requiriendo una participación activa en el diseño imperial que se reflejaba en una solidaridad económica sub specie financiera. Las necesidades de la corona tuvieron un brusco impacto sobre los recursos del Estado, sobre todo porque se tuvo que acudir a la fiscalidad extraordinaria (el mensuale ${ }^{3}$ ), a nuevas enfeudaciones y vías de endeudamiento a corto y largo plazo que repercutieron en cascada desde el centro hasta las más remotas comunidades. Como en Castilla, en Flandes y en Nápoles, también en Milán fueron las condiciones críticas de las cuentas estatales, resultado de acontecimientos político-militares, la causa que empujó hacia la enajenación anticipada de las rentas, siguiendo una característica típica de la política financiera del emperador ${ }^{4}$.

Desde los primeros años 40 del siglo XVI, cuando los otros tipos de financiación — como la venta de jurisdicciones, las asignaciones sobre cuentas futuras y los préstamos a corto plazo - no fueron capaces de afrontar las necesidades crecientes, la venta de las rentas asume un carácter sistemático dentro de la Hacienda milanesa. Este tipo de deuda consolidada, cuyo cobro de los intereses se garantizaba con el rendimiento de los impuestos (founded debt), tuvo un rápido éxito entre los suscriptores (tranquilizados también por el reconocimiento por parte de Carlos $\mathrm{V}$ de las rentas adquiridas en época ducal) y echó sólidas raíces (como por otra parte sucedía en todo el Imperio) porque era mucho más simple y menos arriesgado cobrar los impuestos u otras cargas fiscales — pagados con regularidad y puntualidad en esta primera fase- que hacerse abonar los intereses del gobierno central y fiarse de sus promesas de pago. Por lo demás, después del estado de turbación y revueltas

2 AGS, Estado, leg. 1181, 28 de febrero de 1536 y Carichi ovvero interessi assentati sopra lo Stato di Milano all'entrate ordinarie, 1559. BNF, Mss. italiani, P 239, f. 66,

3 Impuesto extraordinario, que se pagaba precisamente de modo mensual, y que permanecerá hasta el final de la dominación. Después de algunos años de oscilación, en 1547 este tributo se fijó definitivamente en 300.000 escudos (equivalentes a 12 mensualidades de 25.000 escudos), correspondientes a 1.650 .000 liras, convirtiéndose en el ingreso principal de la Regia Cámara milanesa.

4 Entre la abundantísima producción sobre el tema, destacamos CASTILLO PINTADO, (Madrid, 1963): 43-70; TRACY, 1985. CALABRIA, 1991. MUTO, 1995: 251-259. 
ocasionado tras años de guerras, devastaciones militares y peste, al iniciarse los años 40 la recuperación demográfica y económica estaba produciendo un decidido aumento de los ingresos ordinarios, además de ofrecer la posibilidad de crecer los impuestos (a partir de 1556), de crear nuevos o de aumentar la base fiscal $^{5}$. Y a través del efecto multiplicador del sistema de las enajenaciones, la Tesorería ingresaba grandes cantidades de dinero a cambio de cesiones de rentas relativamente modestas. Así también los incrementos de los impuestos o el aumento de los ingresos, que de por sí podían no ser muy significativos, se traducían, para la caja del estado en sumas mucho más importantes, como por ejemplo sucedió con el aumento de 20 sueldos en el impuesto sobre la sal del año 1556, que sumó un total de 136. 211 liras, pero que enajenado en un $12 \%$ hizo ingresar en las arcas ducales un capital de 1.135.096 liras ${ }^{6}$.

Los gráficos 1 y 2, elaborados con los resultados de la consulta de los documentos de venta de las rentas camerales durante la edad española (1535$1700)^{7}$, evidencian claramente que el ritmo de las enajenaciones coincide con las fases de mayor necesidad de las finanzas gubernamentales, marcadas por la guerra, preparada o combatida dentro del ducado o en otros escenarios del imperio. La valoración de este masivo recurso al endeudamiento y del conjunto de su montante (ver Gráfico 3) debe tener en cuenta el proceso inflacionario que caracterizó la segunda mitad del siglo XVI; si desde los años 1555 al 1601 el contenido de plata de la lira de cuenta milanesa pasó de 5, 88 gramos a 5,48, en el siglo XVII, su estabilidad será notable (sólo comparable a la de la moneda toscana) y vendrá acompañada de un prolongado estancamiento de los precios ${ }^{8}$.

5 ALEATI y CIPOLLA, (Milán, 1959): 377-399; VIGO, 1979. DE LUCA, 1996. D’AMICO, (New York, 2000): 1-21.

6 ASMI, Rogiti camerali, cart. 811, año 1556.

7 ASMI, Rogiti camerali, cartt. 809-819.

8 CIPOLLA, 1958: 117. FELLONI, 1999, vol. 1: 485. 


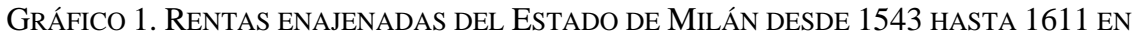
LIRAS IMPERIALES (VALORES NOMINALES)

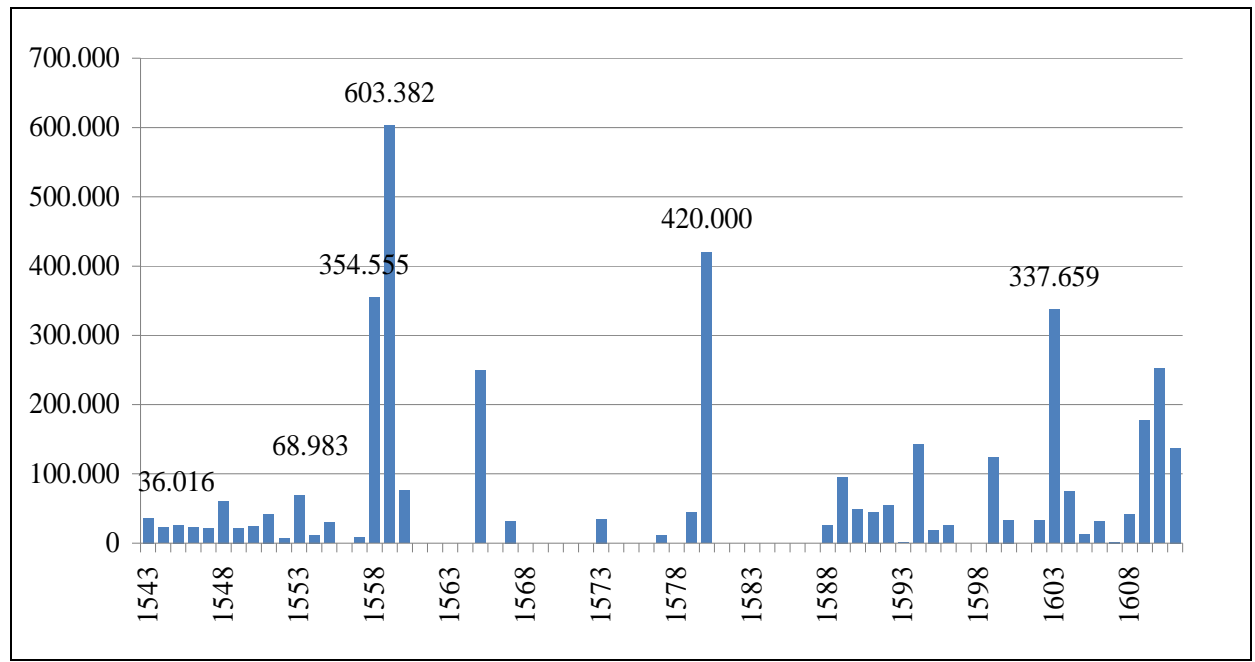

Gráfico 2. Rentas enajenAdas del Estado de MilÁN DESDE 1612 Hasta 1695 EN LIRAS IMPERIALES (VALORES NOMINALES)

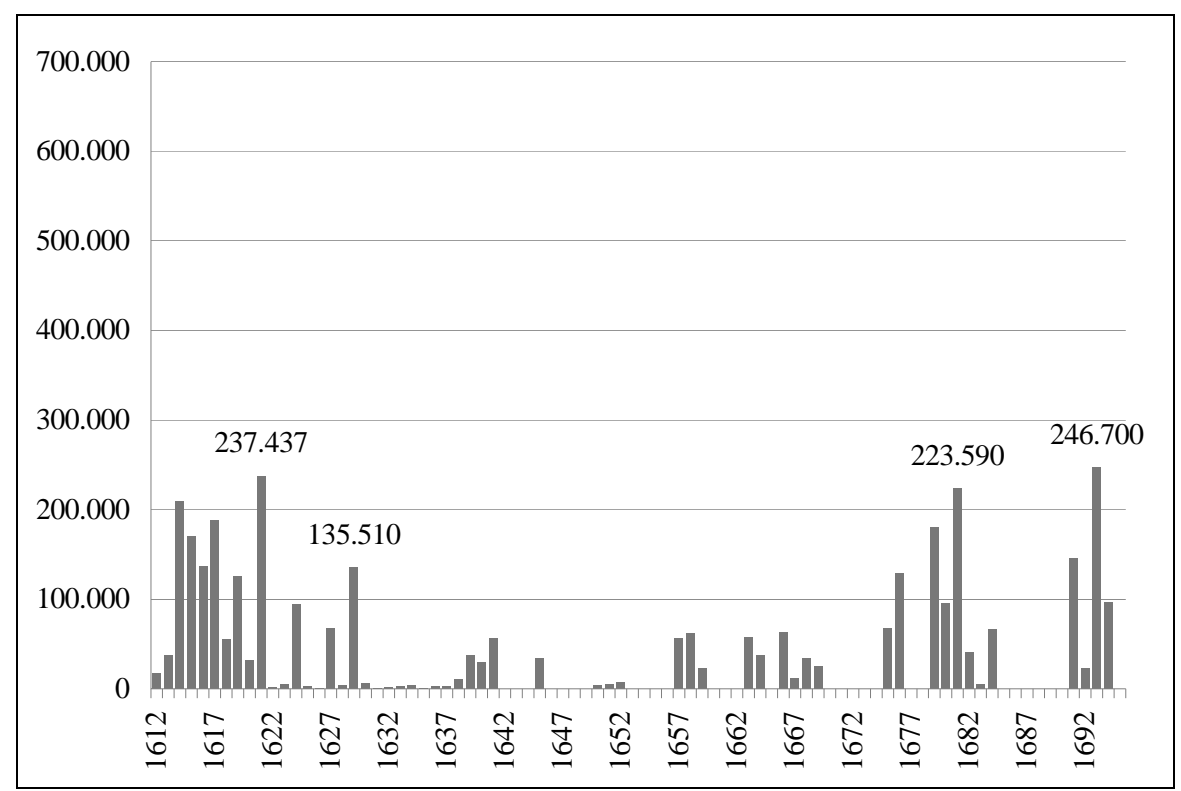

Elaboración propia. Fuente: ASMI, Rogiti camerali, cartt. 809-819. 
GRÁFICO 3. RENTAS ENAJENADAS (INTERESES) Y DEUDA PÚBLICA CONSOLIDADA DEL ESTADO DE MILÁN DESDE 1543 HASTA 1695 EN LIRAS IMPERIALES (VALORES NOMINALES)

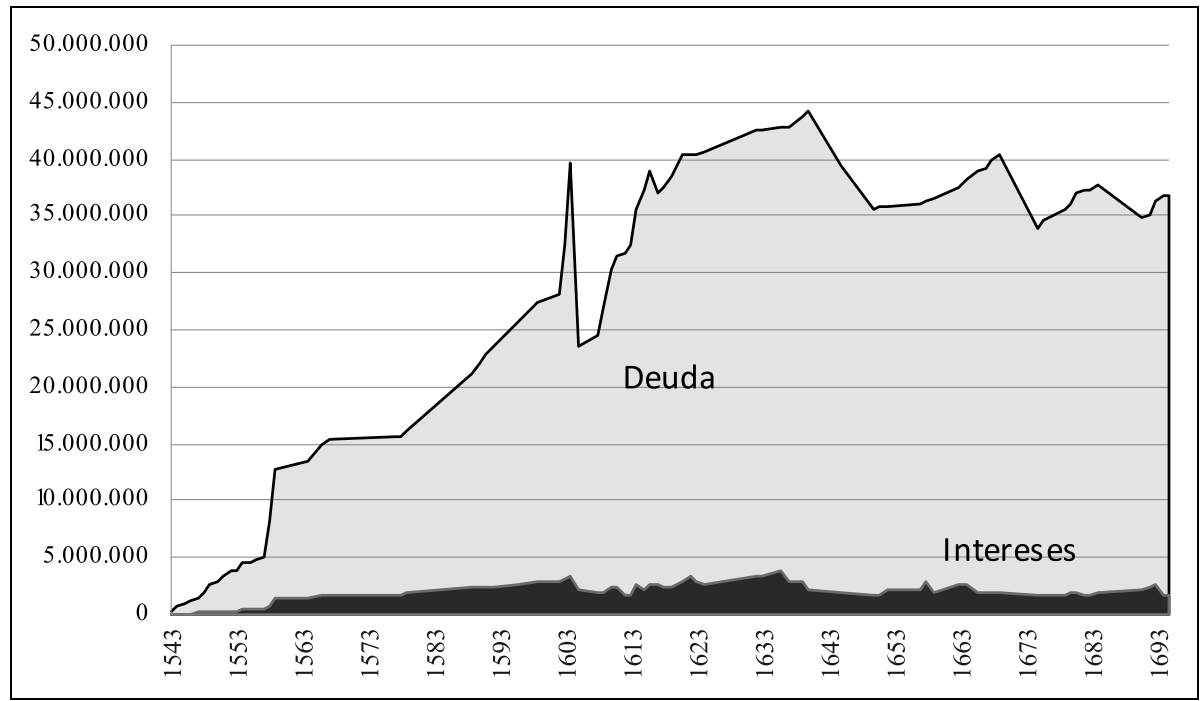

Elaboración propia. Fuente: ASMI, Rogiti camerali, cartt. 809-819.

Entre los años de 1542-1543 la guerra se retomó en todas las fronteras y desde España las ayudas tenían dificultades para llegar: las primeras enajenaciones, desde las de 1543 hasta las de 1545, reflejan las continuas necesidades de la Tesorería en este trance, las cuales no se atenuaron ni siquiera después de la paz de 1544. Las ventas de 1548 (al 5 y al 10 por ciento) reflejan el inicio del período más trágico para el estado milanés desde el punto de vista financiero durante el reinado de Carlos $\mathrm{V}$, mientras que las ventas realizadas entre 1551 y 1553 (efectuadas al 12 por ciento) expresan las necesidades asociadas a la humillación sufrida en Innsbruck ${ }^{9}$. Si en las primeras enajenaciones la parte principal la constituían impuestos recaudados en el campo (como el censo de la sal o la tasa de los caballos, que se podrían definir como impuestos directos), el arancel sobre el comercio al por menor de Milán y algunas gabelas menores, desde finales de los años cuarenta, van a ser los ingresos recaudados en las ciudades los que representen la parte principal de dichas ventas. Durante el dominio del primer soberano español vendrán enajenados anticipadamente ingresos del Estado por valor de más de 412.190 liras, con un interés siempre al alza, que rindieron poco más de cinco millones en su conjunto. A mediados de los años cincuenta, el capital nominal de la deuda

9 CHABOD, 1971: 313-319. 
pública a largo plazo del Ducado, comprendido también el acumulado por los Sforza, alcanzaba los 7.300.407 liras y sus intereses 548.835 liras (lo que suponía el 52 por ciento de los ingresos ordinarios y el 21 por ciento de los ingresos totales) ${ }^{10}$.

Después de la paz de Cateau-Cambresis, Milán pasa a ser definitivamente español y la nueva fidelidad de los lombardos se manifiesta con nuevas emisiones de deuda redimible: durante el año 1559 Felipe II vendió rentas del estado por valor de 1.163.833 liras, elevando el pago de la deuda al 58\% de las rentas ordinarias ${ }^{11}$. En 1560, en línea con la suspensión de pagos decretada en España, se sancionó la reducción forzosa del interés al 5 por ciento de todos los réditos enajenados ${ }^{12}$.

A partir de finales de esa década, la importancia estratégica de Lombardía dentro del tablero europeo creció a raíz de la revuelta flamenca; el estado de Milán se convierte en el corazón del sistema logístico de los Habsburgo en el momento en el que se inaugura el viraje filipino que acrecentará en todos los territorios del imperio español los gastos militares. Y para las finanzas de Lombardía, ligadas indisolublemente a las imperiales, comienza un rápido y notable empeoramiento que afectará en cascada a las finanzas de la ciudad y de los ayuntamientos: como para todos los recursos financieros, también para la enajenación de rentas comienza de este modo un periodo en el que dicha enajenación se convierte en una variable completamente independiente de los ingresos. La buena marcha de la economía del Ducado desde mediados del siglo XVI se venía reflejando en una socialización de la riqueza que permitió aumentar tanto la base fiscal, incrementando el montante de los ingresos (y por tanto las rentas disponibles para su enajenación), como el número de posibles suscriptores; para expandir ulteriormente los ingresos se estaba procediendo paralelamente al establecemiento de nuevos impuestos indirectos (como el dazio della ferrata, un tributo sobre el comercio al por mayor) y a un recrudecimiento de los ya existentes (por ejemplo, el tributo sobre la mercancía se aumentó en un 50 por ciento), es decir, de aquellos tributos que menos afectaban los intereses de los grupos dominantes. En el último decenio del siglo se agudizan las dificultades financieras de la Monarquía: la Hacienda castellana no es capaz de garantizar a la Regia Camera milanesa el envío de las ingentes sumas que necesitaba y así la venta de rentas, a tipos de interés muy desfavorables para el erario, aumenta aún más su peso proporcional.

10 CHABOD, 1981: 318-321.

11 Carichi ovvero interessi assentati sopra lo Stato di Milano all'entrate ordinarie, 1559. BNP, Mss. italiani, P 239, f. 66, y Relatione del sommario dell'entrata ordinaria dell'Estato di Milano dell'anno 1559. AGS, Consejo y Juntas de Hacienda, leg. 24, n. 435,

12 ASMI, Rogiti camerali, cart. 811, año 1560; PUGLIESE, 1924: 339. MUTO, 1995, vol. 1: 287. 
Fracasan o tienen poco éxito los intentos de redenciones para bajar los intereses $^{13}$. Entre 1570 y 1610 la proporción de rentas enajenadas sobre el total de las rentas ordinarias (a pesar de que éstas crecieron constantemente hasta triplicarse durante la segunda mitad del siglo XVI) alcanza porcentajes del 52 al 56 por ciento, con un predominio de tipos de remuneración entre el 8 y el 10 por ciento (ver Tabla 1 ).

En la segunda década del siglo XVII y con el inicio de la primera guerra de sucesión de Mantua, los gastos militares se incrementaron lo que no dejó otra salida que la venta de más de 900.000 escudos de rentas a un interés del 7 por ciento durante el año $1619^{14}$. Pero desde este momento, de cara a la gravísima situación a la que había llegado la Hacienda milanesa (el déficit corriente en 1625 era de casi 1,4 millones de escudos, mientras que el atrasado, o la suma de los déficit anteriores, era de 11,5 millones) y teniendo en cuenta el progresivo agotamiento de la cuota de ingresos todavía disponibles, los comportamientos racionalizadores toman mayor consistencia. La misma administración de los réditos enajenados se reordena en el conjunto de un proceso que afecta a todo el funcionamiento de la Tesoreria regia: por voluntad directa de Felipe III se pone en marcha una eficaz política de rescate de las rentas enajenadas a un mayor tipo de interés; después de la reducción al 5 por ciento de todas las ventas hechas con posterioridad al año 1565, se funda la Caja de redención (cuando en Nápoles se instituye la Caja Militar) dotándola con los depósitos ingresados por quienes querían adquirir regalías y con las fianzas de los arrendamientos ${ }^{15}$.

Tabla 1. Deuda pública consolidada del Estado de Milán y de la República de VeNECIA A FINALES DEL SIGLO XVII

\begin{tabular}{lllllll}
\hline & Año & $\begin{array}{l}\text { Deuda pública con- } \\
\text { solidada }\end{array}$ & $\begin{array}{l}\text { T.int. } \\
\text { medio \% }\end{array}$ & $\begin{array}{l}\text { Intereses/ } \\
\text { Rentas }\end{array}$ & $\begin{array}{l}\text { Deuda/ } \\
\text { Rentas }\end{array}$ & $\begin{array}{l}\text { Deuda en kg } \\
\text { de plata }\end{array}$ \\
\hline Milán & 1695 & liras 36.782 .000 & 4,5 & $39,0 \%$ & 7,5 & 142.346 \\
Venezia & 1679 & ducados 46.300.000 & 3,32 & $35,9 \%$ & 10,8 & 894.748 \\
\hline
\end{tabular}

Fuente: Gráfico 3 infra y Pezzolo, Luciano, Una finanza d'ancien régime. La Repubblica veneta tra XV e XVIII secolo, pág. 88.

Las dificultades que provocó la peste de 1630 y el empeoramiento de la situación militar desde 1636 incidieron después tanto en el camino hacia la reducción de tipos como en la regularidad del pago de los intereses por el esta-

13 MUTO, 1995, vol. 1: 289-91.

14 Enajenaciones de 1619. ASMI, Rogiti camerali, cart. 815.

15 PUGLIESE, 1924: 343. MUTO, 1995, vol. 1: 290-293 y 301. 
do. En 1647 la Cámara, copiando a los montes pontificios, había iniciado una recogida voluntaria de 100.000 ducatones mediante la emisión de luoghi, o títulos, que, sin embargo, sólo se pudieron colocar forzosamente. Cinco años después esta institución se suprime y sus capitales se traspasaron al Monte di San Carlo, instituido en 1638 para asegurar las deudas que el Ducado tenía con el banquero genovés Stefano Balbi ${ }^{16}$.

La consciencia del casi total agotamiento de los ingresos estatales y urbanos, era común en los ambientes madrileños y milaneses; sobre el modelo de los arbitrios españoles, se adelantaron diferentes propuestas para sanear la deuda pública, como la del noble milanés Carlo Girolamo Cavazzi della Somaglia, quien preveía redimir todas las rentas enajenadas en el plazo de cuarenta y ocho años, gracias a la bajada de los tipos de interés que los poseedores habrían aceptado a cambio de un donativo y de la certeza de la restitución del capital ${ }^{17}$.

En la segunda mitad del siglo XVII, la baja rentabilidad de las rentas enajenadas (después de la reducción legal de los tipos al 4 por ciento en el año 1640, al 2 por ciento en 1648, al 5 por ciento por parte de la Caja de la redención en 1643), así como de todas las deudas consolidadas milanesas (las del Banco di Sant'Ambrogio o las de diferentes Montes) ${ }^{18}$ puso en peligro la remunerabilidad de esta clase de inversiones cuyas cotizaciones se hundieron.

Llegados a este punto, únicamente la cesión definitiva de los impuestos representaba una oferta proponible y apetecible: si hasta el año 1646 las regalías cedidas habían sido cincuenta y una, entre ese año y 1649 se vendieron 166 y otras 169 entre 1649 y 1700 (al final de la edad española apenas serán 32 los tributos gestionados directamente por la Cámara) ${ }^{19}$. Únicamente entre 1691 y 1694, durante la crisis de las finanzas públicas provocada por los elevados gastos militares derivados de la guerra de la Liga de Augusta, volvieron a ser vendidas rentas al 7 por ciento, para volver enseguida al más usual interés del 4,5 por ciento $^{20}$. A finales de la época española, la deuda consolidada constituida por el monto de las enajenaciones (una vez descontadas las retroventas efectuadas) alcanzaba los 36.782 .000 liras (7,5 veces los ingresos de un año), mientras que en la República de Venecia representaban casi diez veces los ingresos de un año y sus intereses constituían el 39 por ciento del total de los ingresos ${ }^{21}$. (Ver tab. 1)

16 PUGLIESE, 1924: 346-351. COVA, 1995, vol. 1: 368-377.

17 CAVAZZI DELLA SOMAGLIA, 1648.

18 MUTO, 1995, vol. 1: 291-294. Fondi camerali che erano in amministrazione della Mensa dell'Ill. Magistrato Ordinario alienati dal 1635 avanti. Si comincia nell'anno 1641 per non esservene antecedentemente, BNB, 14. 16 C. 11/5, citado en FACCINI, 1998: 78-81.

19 FACCINI, 1998: 78-81.

20 ASMI, Rogiti camerali, cart. 819.

21 PUGLIESE 1924: 339, afirma que a finales del siglo XVII el total de las rentas enajenadas del Ducado era de 32.304.810 liras. Sobre las difíciles condiciones de la Hacienda 
II. La generalización y el éxito de este tipo de endeudamiento gubernamental - cuyos tiempos y evolución estaban determinados fundamentalmente por las necesidades bélicas - se debieron también a la respuesta dinámica que encontraron entre los adquirientes.

Respecto a la imagen consolidada de una gama de compradores de títulos estatales pertenecientes, para esta época, a las élites políticas y económicas o a instituciones eclesiástico-asistenciales, sorprende en el Estado de Milán la pluralidad y la variedad de sujetos que, al menos durante la primera fase de la dominación española, participaron de estas emisiones. Los más de 1.750 .000 liras de ingresos, enajenado entre 1542 y 1573 lo suscribieron 2.196 individuos diferentes (ver Gráfico 4) y si las sumas mayores fueron adquiridas por banqueros genoveses y locales, nobles y exponentes del patriciado, la cuota más baja, 66 liras sobre el impuesto de los hornos de Milán, acabó en las manos de un sastre de Porta Vercellina, Giovanni Piccardini22 ${ }^{22}$ También en aquellas, vendidas desde 1574 a 1611 por valor de 2.191.302 liras, los compradores fueron más numerosos, 2.640, y el importe medio pasó de 800 a 830 liras). (Ver Gráfico 5).

Por lo demás, la intensa recuperación económica iniciada desde el cuarto decenio del siglo XVI, después del cese de las hostilidades y de las carestías, se estaba traduciendo, sobre todo en la capital ambrosiana, en una evidente distribución de la riqueza: mientras el embajador veneciano observaba que en 1520 existía «gran cantidad de gentilhombres que tienen grandes ingresos hasta de 8 ducados en 10.000», el representante de Ferrara testimoniaba en la segunda mitad de siglo, que Milán era «riquísima; pero de riquezas más bien compartidas por muchos que concentrada en pocos, porque si bien no son más de tres o cuatro las familias que alcanzan los 25 o 30 mil escudos de ingresos y poquísimos los que llegan a 10.000, sin embargo, son infinitos los que tienen 2, 3 o 4 mil escudos de ingresos» ${ }^{23}$. La garantía del pago del interés (recaudado directamente de los contribuyentes y, por tanto, más tranquilizadora que cualquier promesa del gobierno), su cuantía y la transferibilidad constituían elementos persuasivos y tangibles no sólo para banqueros, nobles, patricios y mercaderes, sino también para una amplia gama de artesanos, burócratas, entidades religiosas, mercaderes y mujeres solas que veían en la adquisición de una renta un rédito seguro, regular, no sujeto a impuestos. En esta fase, entre las categorías de los compradores, junto a grandes financieros genoveses (los hermanos Marino, los Centurión, los Spinola, los Grimaldi, los

milanesa en los últimos treinta años del siglo XVII, véase MAFFI, 2010: 185-229, mientras que para el valor de las rentas del Estado a finales de la edad española, véase AGNOLETTO, 2000: 184.

22 Enajenaciones del 2 de septiembre de 1557. ASMI, Rogiti camerali, cart. 811.

23 TABARRINI, (Florencia, 1867): 15. 
GrÁfico 4. PRimeros COMPRAdORES DE LAS RENTAS ENAJENADAS DEL ESTADO DE MiLÁN, 1543-1573 (2.196 INVERSORES)

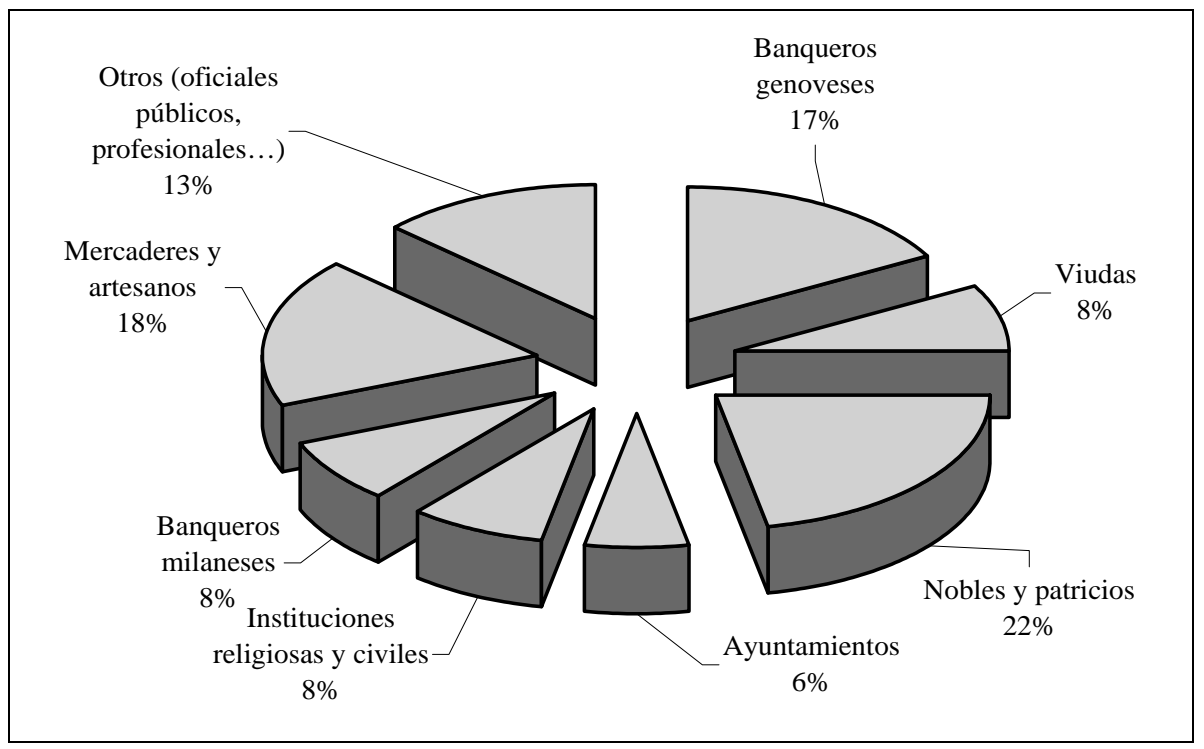

Elaboración propia. Fuente: ASMI, Rogiti camerali, cartt. 809-811.

Balbi), encontramos a las principales figuras de la esfera económica y nobiliaria ciudadana, como Agostino Foppa, los hermanos D'Adda, los mercaderes de lana Carcassola, los Fagnano (activos en Amberes), los condes Camillo y Vitaliano Borromeo, Giovanni Battista Lodrone, Girolamo Sala, el marqués de Gattinara, Giovanni Giacomo Medici (el famoso Medeghino), el presidente del Senado, Pietro Paolo Arrigone; así como a entidades religiosas, asistenciales o lugares píos como la Certosa di Pavia, la Grangia di Chiaravalle, la Certosa di Garegnano, el Ospedale Maggiore di Milano, o instituciones civiles y militares, como el Colegio de los procuradores milaneses y el Hospital militar de Asti, lo mismo que a muchas mujeres, sobre todo aristocráticas, como la duquesa de Lorena, Violanta Lampugnani Visconti, Anna Carcassola, e Isabella Borromeo Trivulzio, pero también de extracción media, como la viuda Caterina Porta que invirtió su dote y sus ahorros para asegurar un ingreso anual a sus jóvenes hijos²4.

24 ASMI, Rogiti camerali, cart. 809-811. El testamento de Caterina Porta puede consultarse en los documentos de los días 14 y 15 de julio de 1623, en ASMI, Notarile, cart. 25522, notario Francesco Girolamo Giusti q. Giovanni. Sobre las dinámicas que llevaban a las viudas a ser nuevas propietarias de capitales, véase CHOJNACKI, 1999: 461-492, y sobre el arquetípico papel de las mujeres únicamente como inversoras de títulos financieros, véase también MURPHY, 2009: 202-207. 
Gráfico 5. PRimeros COMPRAdORES DE LAS RENTAS ENAJENADAS DEL ESTADO DE MiLÁN, 1574-1611 (2.640 INVERSORES)

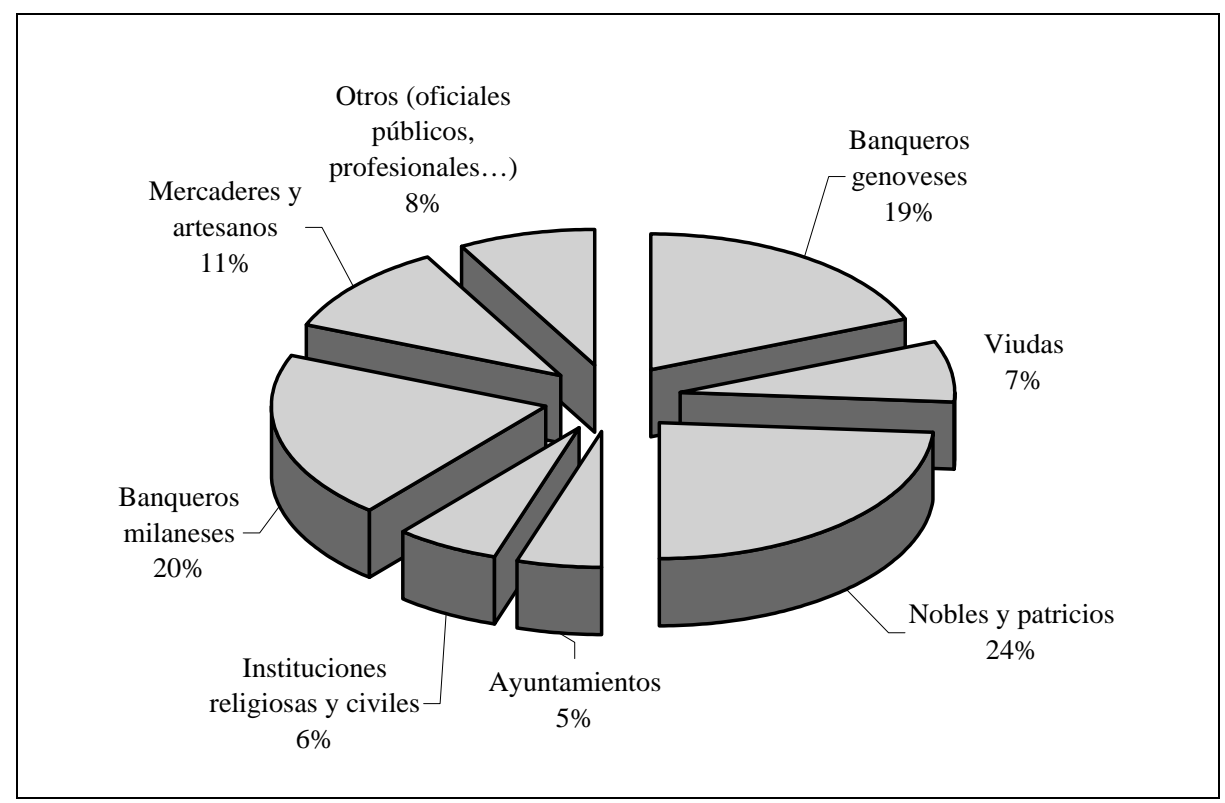

Elaboración propia. Fuente: ASMI, Rogiti camerali, cartt. 812-813.

Aunque muchos títulos vendidos el mismo día del mismo mes y año, disfrutaban a menudo de intereses diferentes — y esto dependía de la calidad del tributo (por ejemplo el censo de la sal de un pequeño ayuntamiento respecto al tributo sobre el comercio al por mayor) y de la cercanía a los centros de poder- las tasas de remuneración eran en muchos casos superiores a las que ofrecían, en el Ducado de Milán, otros tipos de inversión (la renta agrícola disfrutaba, en las áreas mejores de Lombardía, el 2-3 por ciento durante los años sesenta del siglo $\mathrm{XVI}^{25}$ ), y su gama (5-12 por ciento en esta fase) se alineaba con la deuda de otros estados ${ }^{26}$. Además, dado que estos títulos, como veremos en el Párrafo III, podían ser matriz de crédito para obtener préstamos destinados a la actividad empresarial, su adquisición podía hacerse también cuando la tasa de remuneracion no resultaba competitiva, pues ésta precisamente podía compensarse con los usos colaterales de la deuda. Las rentas enajenadas estaban perdiendo en parte su carácter patrimonial y aparecían siempre más claramente como una inversión.

25 PRODI, (Nápoles, 1961): 657.

26 CALABRIA, 1991: 106. PEZZOLO, (Bolonia, 1999): 236. 
En cambio, en la participación de los municipios del ducado en este tipo de deuda también parece actuar, en varios casos, una lógica puramente fiscal: en las diferentes compras realizadas de los dos impuestos «directos» (censo de la sal - cuyo tercio se calculaba sobre la base de los bienes inmuebles - y tasa sobre los caballos y perticato - impuesto proporcional a la extensión de tierras poseídas) que gravaban su territorio, podemos observar el intento de convertir esa carga en impuesto indirecto, obteniendo el ingreso, que se ha comprado, o mediante tributos adicionales (que recaían sobre todos y por tanto aligeraban la carga de los mayores contribuyentes, que eran los grandes propietarios agrícolas) ${ }^{27}$ o de otra forma como demostrarían los casos de Pizzighettone, Voghera, Cerano, Trigolo Cremonese, Casalmaggiore y Vimodrone, donde sus habitantes contaban que «los poderosos habían comprado las rentas para pagar menos de la parte que les correspondía» ${ }^{28}$.

Era, pues, esta variada tipología de compradores la que respondía a alguna enajenación tan rápidamente como para agotar su venta en el transcurso de pocos días; eran sus peticiones las que empujaron al corredor milanés Bernardo Molina, a escribir varias veces a la Regia Cámara, durante las últimas décadas del siglo XVI, para encontrar buenas rentas que vender «essendoci opportuna occasione di compratori» ${ }^{29}$.

Por otro lado, precisamente desde mediados de los años setenta del siglo XVI, aprovechando el momentáneo «enfriamiento» de Felipe II hacia los genoveses y la relativa caída del préstamo a corto plazo, los banqueros-cambistas milaneses - que se consolidan también en virtud de este macroimpulso de la deuda estatal coincidente con la fase expansiva de la economía- estructuran un articulado sistema financiero, que contribuye también a organizar el funcionamiento del mercado del crédito público ${ }^{30}$. Estos operadores — partícipes de la distribución de los asientos- se ocupan cada vez más de la colocación de las rentas enajenadas (sobre su total, ellos participan en el $46 \%$ por ciento, mientras que los genoveses lo hacen en un $21 \%)^{31}$ y del sistema de arrendamiento de tributos, que representaba la natural garantía. Mediante una red de intermediarios locales y de corredores, la demanda abarcaba toda la geografía del estado. Son ellos, junto a los banqueros de la Superba, los protagonistas de un mercado secundario que se muestra especialmente vivaz en esta fase.

27 Véase, por ejemplo, el caso del ayuntamiento de Vimercate, «Memoriale del Magistrato», 18 de mayo de 1602. ASMI, Finanze reddituari, cart. 293, fasc. Carcassola: Para un caso similar referido al Reino de Nápoles, véase Sabatini, 1995: 289.

28 AVDMI, b . B 58, «Memoria degli abitanti di Vimodrone», 25 de agosto de 1645.

29 «Pues existía buena disposición de los compradores». Memoria de Bernardo Molina de 24 de mayo de 1572, ASMI, Finanze reddituari, cart. 3. Sobre los corredores de cambios milaneses, remitimos a DE LUCA, 2010: 239-257.

30 DE LUCA, 1996: 13-49.

31 Enajenaciones del 10 de abril de 1579. ASMI, Rogiti camerali, cart. 811, 
Se trataba de un mercado eficiente desde el punto de vista operativo, con costes de transacción más bajos respecto a otras ciudades italianas: la comisión que los corredores milaneses pedían a cada una de las partes que intervenían en la transacción era del 0,50 por ciento del valor del título y era inferior a la comisión que pedían sus colegas de Bolonia o Roma ${ }^{32}$. Al contrario de lo que sucedía en los territorios papales, el traspaso de propiedad no estaba tasado y el registro en los libros del escribano era gratuito; también las normas que tutelaban a los perceptores de intereses estaban más detalladas y se aplicaban regularmente ${ }^{33}$.

A pesar de que las leyes prescribían que únicamente los ciudadanos del Ducado podían poseer rentas enajenadas, los extranjeros, especialmente los genoveses se incluían entre los compradores ya fuera mediante exenciones específicas ya fuera, en la mayoría de los casos, mediante la adquisición de la civilitas mediolanensis, que conllevaba amplios privilegios fiscales ${ }^{34}$. Sobre la eficiencia informativa del mercado, es decir, sobre el conocimiento de los precios a los que circulaban los títulos, nuestras fuentes sólo nos permiten subrayar la asimetría compartida a favor del emisor y de los banqueros más importantes; uno de los principales puntos de referencia de los pequeños y medios compradores parecía ser precisamente el comportamiento de los sectores dirigentes y de algunas figuras sobresalientes de la sociedad, el cual hacía crecer la confianza general en la estabilidad y rentabilidad de los títulos de deuda pública milanesa ${ }^{35}$.

Aunque todavía no sabemos cuál era la cotización con la que se cedían en el mercado secundario los títulos de deuda, el análisis de los registros referidos a los que percibían réditos nos permite reconstruir la suma de los que cambiaron de dueño después de la emisión: pasados cinco años desde la primera colocación, encontraron un nuevo propietario el 42 por ciento de las más de 600.000 liras enajenadas en el año 1559, el 53 por ciento de las 410.000 liras vendidas en 1581 y el 22 por ciento de las 310.000 liras emitidas en el año 1603; los primeros dos porcentajes aumentaron aún más si se consideran algunos impuestos en particular que formaban parte de las enaje-

32 Memoriale de’ Mercanti di Milano de 18 de enero de 1592. ASCCMI, scatola 32, fasc. 1, Si el corredor proponía al suscriptor la adquisición de una renta directamente de la Cámara, recibía la comisión únicamente del comprador. Sobre las comisiones de los intermediarios boloñeses y romanos, véanse FAROLFI, 1998: 306-322 y COLZI, (Roma, 1998): 397-425.

33 Por ejemplo, el mandato notificado al arrendador Pelegro Doria el 23 de julio de 1601, ASMI, Finanze reddituari, cart. 3.

3431 octubre de 1550. ASMI, Finanze reddituari, cart. 1, y TERRENI, 2006: 105-122. Cuando las urgencias militares apretaban, a los extranjeros se les permitía comprar rentas sin ninguna restricción. Orden de Felipe II de 19 de marzo de 1594. ASMI, Finanze reddituari, cart. 1.

35 El mismo proceso lo podemos encontrar en el mercado de la deuda pública de Amsterdam, 't, HART, 2006. 
naciones (el 87 por ciento del tributo de la mercancía de Milán vendido en 1559 y el 76 por ciento de la aduana mayor de Cremona, enajenada en 1581), demostrando que las rentas más seguras eran las más solicitadas ${ }^{36}$, también fuera de las fronteras italianas; en 1599, en Madrid, el cremonés Leonardo Torriano, ingeniero en los reinos de Portugal, vendió a Juan de Herrera un título sobre el tributo de la mercancía de Milán de 1.700 liras y 18 sueldos $^{37}$.

Con la llegada del segundo decenio del siglo XVII, el número de los compradores directos disminuyó drásticamente a favor de los grandes financieros genoveses y milaneses, que se ocupaban de recolocar después las enajenaciones. Las necesidades de la Cámara, especialmente urgentes en esos años, hacía preferible las enajenaciones de grandes sumas de una sola vez a estos operadores que las ventas directas al público. Pero la reducción constante de los intereses, puesta en marcha en aquellos años, y la inseguridad sobre las condiciones generales de la Hacienda, que a comienzos de 1630 suspendió en más de una ocasión, parcial o íntegramente, el pago de las rentas ${ }^{38}$, redujeron el atractivo y la vivacidad del mercado de los títulos estatales, los cuales debieron sufrir también la competencia de los títulos municipales emitidos por el Banco de San Ambrosio (fundado en 1593) 39.

Además la reorganización estructural de la economía lombarda, con el telón de fondo de las mutaciones macroestructurales europeas, desplazaba progresivamente su centro de gravedad hacia la exportación de productos semielaborados y originaba una acentuada polarización tanto de la riqueza como de los actores implicados; las enajenaciones de rentas cada vez eran más difíciles de colocar y pocos son los testimonios de entonces que hablen de traspasos sucesivos. En estos decenios junto a los genoveses (Balbi y Durazo a la cabeza) operarán un puñado de grandes banqueros locales capaces de gestionar la deuda como contrapartida de los asientos contratados con la Corona. Se observa también la tendencia a la concentración de los réditos mediante el rescate o el cambio en los registros contables de cuotas. En 1641 Carlo Franceso Ceva, procurador de un consorcio de rentistas genoveses, acaparó las rentas de todos los hornos de Milán, de los molinos camerales, de los yesos y de otras rentas para permitir a la Regia cámara rescatar los réditos en manos

36 ASMI, Rogiti camerali, cartt. 812-813.

37 Notario Luis Erviar, documento fechado el 8 de junio de 1599. AHPM, protocolo 2812, f. 598.

38 MUTO, 1995: 288-293. La costumbre de pagar únicamente diez meses de intereses se convierte en algo habitual desde 1635, ASMI, Li ragionati generali della Regia duc. Camera dello Stato di Milano, 4 de abril de 1635. Finanze reddituari, cart. 10,; desde 1639, se pagarán sólo nueve meses de intereses, Li ragionati generali della Regia duc. Camera dello Stato di Milano», 13 de enero de 1639. ASMI, Finanze reddituari, cart. 12.

39 COVA, 1995: 363-381. 
de los Omodei $^{40}$. También en una operación de retroventa, cinco años más tarde, el habitante de Como Gerolamo Turconi realiza una operación especulativa que le rinde 200.000 liras $^{41}$. En 1685, la exacción sobre las rentas percibidas por los extranjeros golpeó a los súbditos de Génova, que también por otras gravosas contribuciones comenzaron a reducir su antigua presencia en la deuda pública ducal ${ }^{42}$.

Pero para los naturales del estado, las enajenaciones camerales desempeñaron aún, durante la gran estabilidad de los precios del siglo XVII, una función importante asegurando una de las remuneraciones más ventajosas y protegiendo de una exacción cada vez más invasiva los propios réditos, como así destacaba, en la segunda mitad del Seiscientos, Francesco Bigatti (autor de un proyecto de reforma de los impuestos del Estado) cuando subrayaba que los compradores de las rentas ingresaban sus intereses y «reían, mientras todos los demás, bajo el peso de las cargas, lloraban» ${ }^{43}$.

III. Teniendo en cuenta, pues, la buena acogida que este nuevo tipo de deuda pública encontró entre los compradores, es necesario preguntarse si la gran cantidad de dinero que acabó en las enajenaciones milanesas o en los depósitos sobre la casa de la moneda veneciana, sustrajo capitales a la inversión privada a largo plazo destinada a la economía real y/o aumentó sus costes.

Si partimos de la hipótesis de que, en el caso del Ducado de Milán, la demanda de capitales a largo plazo por parte de los empresarios se cubrió con censos consignativos firmados con los banqueros locales, podemos establecer su evolución durante el periodo que va desde 1575 a 1611, con seguridad el de mayor expansión económica del Estado entre los siglos XVI y XVII ${ }^{44}$. Como es sabido, en 1569 la Bula Plana de Pio V había sancionado este tipo de contrato de préstamo, basado en garantías reales, redimible y articulado bajo la fórmula empio cum locatione, según la cual el capital prestado se configuraba como el precio de la venta de un bien del deudor, después concediéndole en alquiler por el acreedor a cambio del pago de una renta o interés ${ }^{45}$. Los censos localizados en

40 ASMI, Finanze reddituari, cart. 622 (fasc. Emilio Omodei) y BORLANDI, 1989: 53.

41 En 1712, la Comisión regia — creada por los austríacos para controlar todos los contratos entre la Real Cámara y los particulares-, señalaba que en 1646 Gerolamo Turconi había adquirido rentas anuales por valor de 48.444 liras y por un capital de 954.906 liras; de esta cifra había desembolsado a la Cámara sólo 69.891 liras al contado, mientras que el resto se había contabilizado como deuda adelantada del Estado; pero esta deuda se había calculado en una moneda que tenía un valor nominal mayor de aquella en la que se habían efectuado los diferentes préstamos, por lo que el valor del crédito ascendía sólo a 823.959 liras. Informes de la Comisión de los días 12, 15 y 29 de enero de 1712. ASMI, Finanze p.a., cart. 91,

42 FELLONI, 1971: 214.

43 Citado en PUGLIESE, 1924: 183.

44 D’AMICO, 2000: 4-21.

45 DELUMEAU, 1959, vol. 2: 870-873. ALONZI, (Nápoles, 2005): 86-102. 
el periodo citado, 1575-1611, alcanzan la cifra de 241 y su total suma 2.116 .000 liras (ver Gráfico 6), con un interés del 7\% para aquellos que duran 20 años y del 9\% para los que duran 10 (más abundantes a partir de 1595). Hasta los primeros años noventa del siglo XVI, los prestatarios o quienes reciben el préstamo son casi exclusivamente empresarios siderúrgicos que utilizan los capitales obtenidos de este modo para implantar minas y hornos de fundición en Valsassina, mientras que en los dos decenios sucesivos son sobre todo mercaderes que usan esos capitales para poner en marcha «lavoreri» de seda (establecimientos para

GRÁfico 6. DEUdA PÚBliCa y CENSOS CONSIGNATIVOS EN El EstAdo de MilÁN (15751611) EN LIRAS IMPERIALES (VALORES NOMINALES)

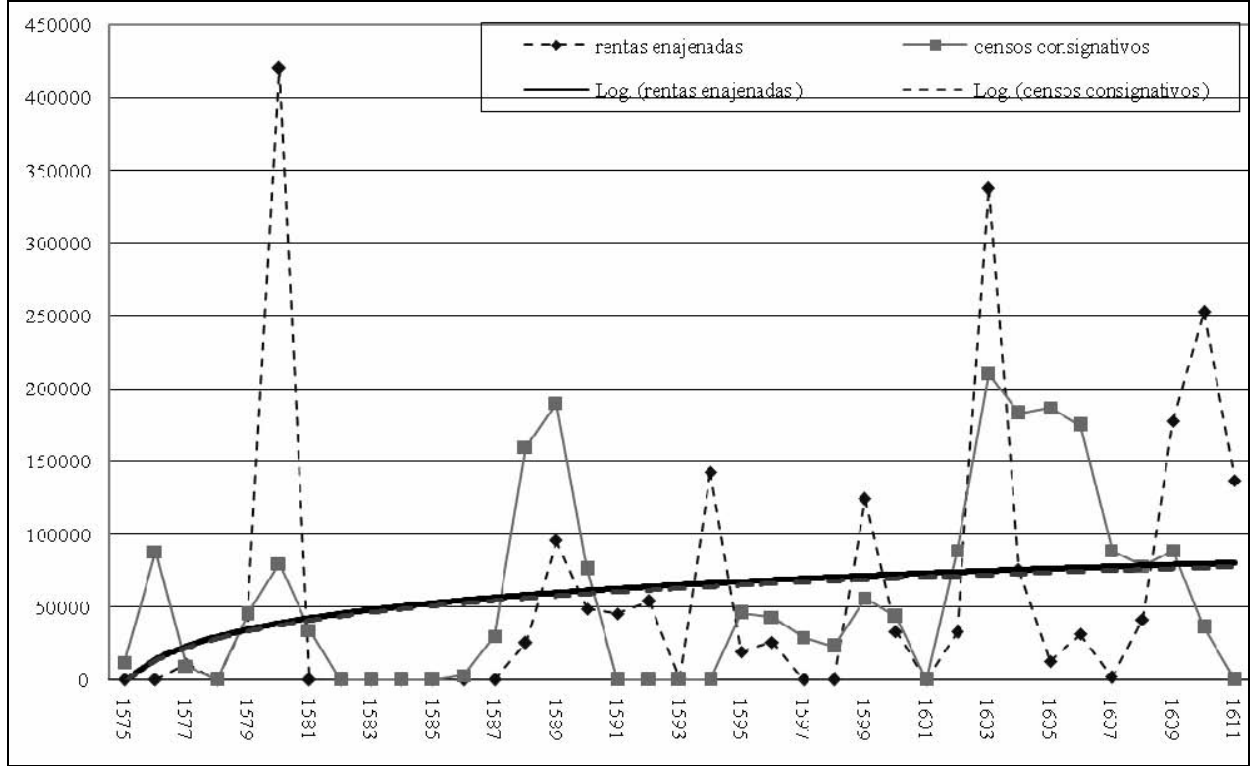

Elaboración propia. Fuente: para las rentas enajenadas ASMI, Rogiti camerali, cartt. 809-813; para los censos consignativos ASMI, Notarile, cartt. 13092-13102 (1576-1588) notario Rolando Mazza; 13710-13711 (1575-1577) Giovanni Battista Bombelli; 13880-13895 (1575-1597) Dionigi Oldoni; 14766-14784 (1575-1594) Ambrogio Ferni; 14922-14929 (1591-1598) Ventura Solari; 14937-14944 (1575-1584) Ottaviano Castelletti; 15432-15441 (1575-1591) Giacomo Filippo Cattaneo Vaiani; 15505-15515 (1575-1601) Cesare Borsani; 15505-15515 (1575-1607) Cesare Borsani; 16296-16300 (1575-1607) Bernardo Quarantini; 16471-16483 (1575-1598) Giovanni Giacomo Fedeli; 16612-16623 (1575-1606) Cesare Guidi; 16939-16958 (1575-1607) Francesco Massarola; 17030-17031 (1573-1608) Polidoro Mantelli; 17569-17581 (1575-1592) Giovanni Paolo Pellizzari; 17676-17683 (1575-1607) Girolamo Martini; 17782-17787 (15751607) Benedetto Barbavara; 18928-18938 (1575-1607) Paolo Girolamo Fontana; 19594-19603 (1578-1607) Giovanni Battista Baruffi; $20651-20667$ (1583-1611) Giuseppe Martignone; 23715-23719 (1597-1611) Dionigi Capra; $23821-23824$ (1597-1604) Pietro Luigi Merlato; 23950-23956 (1598-1611) Francesco Rugginelli; 23982-23991 (1598-1611) Giovanni Ambrogio Caccia; 24779-24780 (1603-1611) Francesco Brofferio, ad vocem censo. 
las primeras fases de elaboración de la seda). Pasado el primer decenio del siglo siguiente este instrumento de crédito se reducirá notablemente dentro del mundo mercantil que se decantará por la comandita, quedando el censo como fórmula prevalente en el endeudamiento de los municipios.

Con estos datos, la curva de los capitales para la actividad productiva presenta una línea de tendencia claramente creciente y sustancialmente coincidente con la de los capitales destinados al crédito público en la misma fase (ver Gráfico 6). Los dos tipos de demanda aumentan pues, conjuntamente, y esto debido al hecho de que la cantidad de moneda en circulación crece, como lo testimonian tres hechos; ante todo - aunque es bastante complicado calcular el efecto real acumulativo de las nuevas acuñaciones no sabiendo cuánto supusieron las retiradas de moneda, y resulta poco fiable sumar valores de moneda acuñada en momentos diferentes - no hay duda que la tendencia de las nuevas emisiones era al alza: ya en 1542-1554, se registra una expansión que alcanza su cenit entre los años 1580-1591, cuando se acuñan casi 30 millones de liras y cuando en la década siguiente se ponen en circulación unos 2046; en segundo lugar, diversos testimonios indican que los saldos de la balanza de pagos fueron muy positivos hasta la segunda década del siglo XVII como consecuencia de los consistentes flujos de las exportaciones ${ }^{47}$; finalmente, entre finales del siglo XVI y principios del XVII, la circulación de las «pólizas de crédito» aumenta, pues «se suelen hacer por cualquier deudor a favor del acreedor, tanto de modo impreso como en forma de billete» y «pasan de una mano a otra como si fuesen dinero en efectivo» ${ }^{48}$, ahorrando el uso de la moneda metálica en las transacciones mercantiles e incrementando la circulación global de este modo.

En estos decenios a caballo entre los siglos XVI y XVII, en uno de los más prósperos ciclos económicos milaneses, basado en una articulada estructura productiva y alimentado por un fuerte flujo de exportaciones de sedas preciosas, la demanda pública de capitales no hundió la demanda privada; los dos componentes tocan la curva de la oferta en puntos diferentes, con una ventaja en términos de tipo de interés a favor de la segunda, de la privada (7-9 por ciento, frente al 8-10 por ciento). El precio del dinero para los particulares era ligeramente inferior ya fuera por el menor tiempo de duración del préstamo ya fuera por la garantía real ofrecida (en el momento mismo de estipular un censo, el prestamista se convertía en propietario del bien puesto en garantía). Además, la tasa de remuneración de la deuda estatal tendía, durante esta fase,

46 CIPOLLA, 1952: 42-47, 90. GARCÍA GUERRA, 2000: 245-255.

47 De hecho, gran parte de las nuevas acuñaciones de moneda están ligadas a la demanda privada, VIGO, XVIII/4 (Nápoles, 1976): 113-126.

48 Attestato de’ signori negozianti della Piazza di Milano, del 6 de diciembre de 1663. ASCCMI, scatola 2, fasc. 42, 
a adecuarse a las urgencias político-militares y se veía reducida en una parte por el factor riesgo del que los banqueros milaneses eran conscientes, sobre todo después de las primeras crisis de las finanzas españolas. El circuito que gestionaba el encuentro entre la recogida de capitales y la oferta de inversión estaba, efectivamente, en manos de un grupo de operadores que recibían el dinero recogido por los cambistas, con los que estaban asociados, por las viudas, que invertían en cambios, por los poderosos, por los nobles y por los patricios; y lo dirigían ya fuese hacia el crédito privato ya fuese hacia la deuda pública flotante o consolidada ${ }^{49}$.

Además, durante esta fase, los títulos estatales constituirán mayoritaria o exclusivamente los bienes que el deudor vendía en el censo consignativo al prestamista a cambio del crédito; en los censos estipulados por nuestros empresarios-mercaderes entre 1575 y 1611, el total de rentas que venían «provisionalmente» cedidas con esta función alcanzaba las 379.850 liras (ver Gráfico 6). Para los prestamistas el riesgo financiero se reducía considerablemente y los títulos de deuda pública a largo plazo representaban no sólo beneficios adicionales y exención de impuestos, sino matrices de crédito que aumentaban las posibilidades de los sectores productivos de obtención de otros fondos; tenían, sustancialmente, un efecto procíclico para las inversiones privadas. Este uso lo ratifican también las Ordenanzas de la Cámara de los Mercaderes de Milán de julio de 1572, en las que se especifica que para que sobre los «tributos y rentas del estado de los que se obtiene un interés», se pueda constituir un censo, debe producirse el pateat con el que el deudor ha entrado en posesión ${ }^{50}$. Extendiendo el espectro de las conexiones entre deuda pública y economía real, podemos considerar los posibles efectos que la política del déficit de gasto, permitida también por esta forma de endeudamiento (además de por los «socorros o ayudas» enviados por otros dominios españoles), tuvo en la economía de la Lombardía española. Entre las dos posibles alternativas —que el déficit de gasto, actuando en una economía caraterizada por el pleno empleo, haya sustraído factores de producción a los sectores civiles estimulando la inflación, o que, por el contrario, haya movilizado recursos inactivos hacia el ámbito militar- el hecho de que los precios y los salarios reales hayan permanecido estables a lo largo del siglo XVII (y aún descendieran después de 1620) hace que prevalezca la segunda hipótesis. En el Ducado el masivo gasto bélico (vestimenta, armas, fortificaciones) empleó a una mano de obra suplementaria

49 DE LUCA, 1996: 50-60.

50 Attestato della Camera de Mercanti di Milano, 9 de julio de 1572.ASCCMI, scatola 2, fasc. 9, Desarrollos sucesivos de una similar utilización de los títulos públicos en otros países, confirman los beneficios potenciales de estos instrumentos y de su mercado, GELDERBLOM y JONKER, 64/3 (Cambridge, 2004): 641-672. 
y creó nuevos flujos de renta que a su vez contribuyeron a mantener alta la demanda civil de bienes y servicios, sobre todo en las ciudades ${ }^{51}$.

Desde finales del segundo decenio del siglo XVII, con el cambio del ciclo económico - ligado a los nuevos ejes macroeconómicos del contexto europeo- la articulada estructura del sistema urbano se reajustó sobre un nuevo equilibrio agrícola-mercantil basado en el balance entre importaciones y exportaciones de productos semielaborados (especialmente seda en hilos). Los intereses económicos de los sectores sociales más acomodados y de las élites dirigentes se alinearon en esta dirección, mientras las oportunidades de movilidad social se redujeron, produciéndose una gradual polarización ${ }^{52}$. En este contexto, la deuda pública consolidada ofreció, junto a la renta agrícola, buenos rendimientos y se salvaguardó de la creciente presión fiscal; protegió los patrimonios y las dotes (civiles y religiosas) de la clase dirigente, y sostuvo tanto el gasto suntuario como los gastos productivos. El inversor en rentas enajenadas y el arrendador-empresario (que se va delineando como consecuencia de la difusión de este tipo de deuda) se perfilan como los protagonistas de un largo recorrido hacia la modernización capitalista, basado en comportamientos individuales cada vez más «destructivos» de las predominantes relaciones no mercantiles de status, y que cada vez tenían más en cuenta la valoración del riesgo y la racionalidad económica en el diseño de las estrategias de inversión. Este sistema de endeudamiento puede interpretarse, en algunos aspectos, como una especie de laboratorio en el que prácticas arraigadas, reflejo de comportamientos típicos de sociedades proto-capitalistas, conviven con elementos innovadores capaces de actuar como posibles viveros de prácticas empresariales modernas ${ }^{53}$.

En 1582 la recaudación de los impuestos principales como el estanco de la sal, la aduana mayor de Cremona, pero sobre todo, el tributo sobre el vino al por menor en Milán y el de la mercancía, eran grandes empresas que exigían una multitud de empleados y colectores que requerían una organización articulada y compleja; quienes controlaban estas actividades eran personajes del calibre de Cesare Negrolo, Tommaso D’Adda y Rinaldo Tettoni, los Litta, los Melzi, Pelegro Doria, que eran los más importantes empresarios del Estado (de la seda, del comercio, etc.), y que de este aprendizaje pasarán a gestionar «industrias más modernas» como la extracción y fundición del hierro en Valsassina en el caso de los Cipriani, anteriormente arrendadores del impuesto de las moliendas. Todavía en los primeros años veinte del siglo XVII, la recaudación del tributo sobre el vino al por menor y de la mercancía estará en las manos de Marcantonio Stampa

51 SELLA, 1982: 119-120.

52 MOIOLI, 1998: 32-55.

53 AGNOLETTO, 2000: 59-75. 
y después de los Omodei, que harán girar toda su fuerza económica y financiera precisamente hacia el arrendamiento de los impuestos milaneses ${ }^{54}$.

IV. El genotipo de deuda pública que se desarrolló en Milán, a partir del cuarto decenio del siglo XVI, surge en toda su ramificada multifuncionalidad y ocupa un papel central en las complejas interconexiones que unen la gestión del poder con la estratificada sociedad local, que vinculan el sistema fiscal con la estructura y coyunturas económicas, las necesidades militares con los intereses de las élites locales y con sus estrategias de afirmación y conservación.

En términos económicos, el coste del crédito para el Estado fue bastante moderado y en la segunda mitad del siglo XVI los gobiernos del Ducado fueron capaces de obtener dinero desde el 4,5 al 11,4\%. Además el intercambio de los títulos contribuyó a que aparecieran sofisticadas formas de especulación y estimuló posteriores innovaciones en el comercio del dinero. No obstante, buscar rasgos de presente racionalidad y de moderna eficiencia en un mercado financiero caracterizado por elementos que hoy podríamos definir como extra-económicos, constituido por gobernantes y gobernados que perseguían más la justicia distributiva que la commutativa y marcado por tipos de interés que respondían más a lógicas de reciprocidad que a la disponibilidad de capitales, sería cuanto menos impropio. La credibilidad y confianza (de todas formas bien garantizada) que los prestamistas milaneses concedían a sus gobiernos, determinando el éxito de la deuda pública, ahondaba sus raíces precisamente en este tipo de sociedad en el que la clase dirigente y el vértice económico eran un todo. La política de gestión de los Austrias se tradujo en una sustancial (aunque cambiante) alianza con la cúpula del poder autóctono y en un apoyo a sus decisiones en el ámbito económico. Nada más tomar posesión Carlos $\mathrm{V}$ del territorio milanés y todavía aún cuando la sensación de precariedad respecto al destino del Ducado estaba muy difundida, una de las primeras cosas que pidieron los súbditos milaneses y que les fue rápidamente concedida fue la confirmación y mantenimiento de todas las ventas de rentas efectuadas con anterioridad. A pesar de la progresiva concentración de la deuda en las manos de grandes poseedores, a mediados del siglo XVII los pequeños y medianos inversores componían todavía una parte importante del mercado milanés de las rentas, al contrario de lo que estaba sucediendo en Nápoles; en 1639, en la ciudad de San Ambrosio il 24 por ciento de la deuda consolidada estaba constituido por ingresos inferiores a las 150 liras y estaba en posesión de unos 4.350 individuos, de los que 77 eran comunidades. A mediados del siglo XVII el ducado milanés fue el único dominio de la Monarquía española que no conoció una revuelta política o social contra la corona o una significativa conspiración anti-habsbúrgica, aunque no faltaron con-

54 Para conocer cada una de las trayectorias empresariales de estos arrendadores, remitimos a DE LUCA, 1996: 41-46. 
flictos y enfrentamientos ${ }^{55}$. Las clases inferiores y medias, las pequeñas y medianas ciudades y los diferentes municipios ${ }^{56}$ - que percibían intereses de la deuda pública, junto al patriciado, a los mercaderes, a los banqueros y a las instituciones religiosas y civiles - no tenían nada que ganar rebelándose contra un gobierno al que concedían créditos y del que recibían rentas. La deuda pública constituyó uno de los garantes más importantes para la conservación de la estabilidad social y política, desempeñando un papel central en la peculiar e ininterrumpida quietud del Milanesado.

Madrid, siguiendo un rasgo común a casi todos sus dominios italianos, implicó a las élites dirigentes locales en un mecanismo de redistribución de la renta, que perseguía la progresiva integración sub specie oeconomica de estas élites en las decisiones políticas centrales.

TABLA 2. INTERESES NOMinALES DE VENTAS DE LA RENTAS DEL EsTADO DE MiLÁN, 1543-1694 (VALORES MEDIOS PONDERADOS)

\begin{tabular}{cccccc}
\hline AÑO & I.NOM. & AÑO & I.NOM. & AÑO & I.NOM. \\
\hline 1543 & 7,9 & 1573 & 10,0 & 1606 & 8,0 \\
1544 & 9,4 & 1577 & 10,0 & 1607 & 8,0 \\
1545 & 9,6 & 1579 & 9,2 & 1608 & 8,0 \\
1546 & 10 & 1581 & 9,4 & 1609 & 7,6 \\
1547 & 7,4 & 1588 & 8,6 & 1610 & 7,8 \\
1548 & 7,6 & 1589 & 8,3 & 1611 & 7,7 \\
1549 & 6,6 & 1590 & 5,4 & 1612 & 5,0 \\
1550 & 7,5 & 1591 & 7,9 & 1613 & 5,0 \\
1551 & 7,9 & 1592 & 5,8 & 1614 & 7,6 \\
1552 & 12 & 1593 & 7,0 & 1615 & 6,1 \\
1553 & 12 & 1594 & 10,0 & 1616 & 7,0 \\
1554 & 12 & 1595 & 11,1 & 1617 & 7,0 \\
1555 & 12 & 1596 & 9,0 & 1618 & 6,5 \\
1557 & 11,9 & 1599 & 7,0 & 1619 & 6,5 \\
1558 & 11,5 & 1600 & 7,3 & 1620 & 6,5 \\
1559 & 12,8 & 1602 & 8,0 & 1621 & 7,0 \\
1560 & 12,0 & 1603 & 8,0 & 1622 & 8,4 \\
\hline
\end{tabular}

55 SIGNOROTTO, 1996: 721-745.

56 Desde las primeras décadas del siglo XVII muchos ayuntamientos del Ducado prestaron grandes cantidades de dinero mediante censos a la Tesorería milanesa, véase Faccini, Luigi, La Lombardia fra ‘600 e '700, págs. 54-63; GIANNINI, 2001: 99-162. 


\begin{tabular}{cccccc}
\hline AÑO & I.NOM. & AÑO & I.NOM. & AÑO & I.NOM. \\
\hline 1565 & 17,0 & 1604 & 8,0 & 1623 & 7,0 \\
1567 & 7,9 & 1605 & 8,0 & 1624 & 6,5 \\
1625 & 6,5 & 1639 & 6,8 & 1668 & 5,0 \\
1626 & 6,5 & 1640 & 5,0 & 1669 & 5,0 \\
1627 & 6,5 & 1641 & 5,0 & 1675 & 5,0 \\
1628 & 6,5 & 1645 & 5,0 & 1676 & 5,0 \\
1629 & 6,5 & 1650 & 5,0 & 1679 & 5 \\
1630 & 6,5 & 1651 & 5,0 & 1680 & 5 \\
1631 & 6,5 & 1652 & 6,0 & 1681 & 5,3 \\
1632 & 7,8 & 1657 & 6,0 & 1682 & 4,5 \\
1633 & 8,0 & 1658 & 7,8 & 1683 & 4,5 \\
1634 & 8,0 & 1659 & 5,0 & 1684 & 4,8 \\
1635 & 8,0 & 1663 & 7,0 & 1691 & 6,5 \\
1636 & 9,0 & 1664 & 7,0 & 1692 & 7 \\
1637 & 7,0 & 1666 & 5,0 & 1693 & 7 \\
1638 & 7,0 & 1667 & 5,0 & 1694 & 4,5 \\
\hline
\end{tabular}

\section{BibLIOGRAFÍA}

Agnoletto, Stefano, "The Spanish Heavy Tax-Regime: a Constraint on Capitalistic Modernization or a Matrix for Innovation? An Aspect of Accumulation in the State of Milan at the End of the Spanish Domination (1706)", en Giuseppe De Luca y Gaetano Sabatini (coords.), Growing in the Shadow of an Empire. How Spanish Colonialism Affected Economic Development in Europe and in the World (XVI ${ }^{\text {th }}$ $X V I I I^{\text {th }}$ cc.), Milano, FrancoAngeli, 2012; 59-75.

Agnoletto, Stefano, Lo Stato di Milano al principio del Settecento. Finanza pubblica, sistema fiscale e interessi locali, Milano, FrancoAngeli, 2000.

Aleati, Giuseppe y Cipolla, Carlo Maria, “Aspetti e problemi dell'economia milanese nei secoli XVI e XVII”, en Storia di Milano, XI, Milano, Fondazione Treccani degli Alfieri, 1959; 377-399.

Alonzi, Luigi, "I censi consegnativi nel XVI e XVII secolo tra 'finzione' e 'realtà'”, L’Acropoli, VI/1 (Nápoles, 2005): 86-102.

Borlandi, Antonia, “'Al Real Servitio di S. Maestà’. Genova e la Milano del Seicento", en: Aldo De Maddalena (coord.), "Millain the great". Milano nelle brume del Seicento, Milano, 1989; 41-60.

Calabria, Anthony, The Cost of Empire. The Finances of the Kingdom of Naples in the Time of Spanish Rule, Cambridge, Cambridge University Press, 1991. 
Castillo Pintado, Álvaro, "Los juros de Castilla. Apogeo y fin de un instrumento de crédito”, Hispania, XXIII/89 (Madrid, 1963): 43-70.

Cavazzi della Somaglia, Carlo Girolamo, Nuova inventione certissima, e facilissima per liberare la città di Milano e le provincie dello Stato da loro debiti senza cagionare alcuna Gravezza ma ben sì evidente, ed universale utilità, Milano, Filippo Ghidolfi, 1648.

Chabod, Federico, Storia di Milano nell'epoca di Carlo V, Torino, Einaudi, 1971.

Chojnacki, Stanley, "Riprendersi la dote: Venezia, 1360-1530”, en Silvana Seidel Menchi, Anne Jacobson Schutte y Thomas Keuhn (coords.), Tempi e spazi di vita femminile tra medioevo ed età moderna, Bologna, Il Mulino, 1999; 461-492.

Cipolla, Carlo Maria, Le avventure della lira, Milano, Edizioni di Comunità, 1958.

Cipolla, Carlo Maria, Mouvement Monétaires dans l'Etat de Milan (1580-1700), Paris, Armand Colin, 1952.

Colzi, Francesco, “'Per maggiore facilità del commercio’. I sensali e la mediazione mercantile e finanziaria a Roma nei secoli XVI-XIX”, Roma, VI/3 (Roma, 1998): 397-425.

Cova, Alberto, "Banchi e monti pubblici a Milano tra interessi privati e pubbliche necessità”, en Paolo Pissavino y Gianvittorio Signorotto (coords.), Lombardia borromaica Lombardia spagnola 1554-1659, Roma, Bulzoni, 1995, vol. I; 368-381.

D’Amico, Stefano, “Crisis and trasformation: economic reorganization and social structures in Milan, 1570-1610”, Social History, 25/I (New York, 2000): 1-21.

De Luca, Giuseppe, Commercio del denaro e crescita economica a Milano fra Cinquecento e Seicento, Milano, Il Polifilo, 1996.

De Luca, Giuseppe, “Sensali e mercato del credito a Milano tra XVI e XVII secolo”, en Elena María García Guerra y Giuseppe De Luca (coords.), Il mercato del credito in età moderna. Reti e operatori finanziari nello spazio europeo, Milano, FrancoAngeli, 2010; 239-257.

Delumeau, Jean, Vie économique et sociale de Rome dans la seconde moitié du XVIe siècle, Paris, Boccard, 1959.

Faccini, Luigi, La Lombardia fra '600 e '700. Riconversione economica e mutamenti sociali, Milano, Franco Angeli, 1988.

Farolfi, Bernardino, "Brokers and Brokerage in Bologna from the Sixteenth to the Nineteenth Century”, en Alberto Guenzi, Paola Massa, Angelo Moioli y Fausto Piola Caselli (coords), Guilds, Markets and Work Regulations in Italy, $16^{\text {th }}-19^{\text {th }}$ Centuries, Aldershot, Ashgate, 1998; 306-322.

Felloni, Giuseppe, "Finanze statali, emissioni monetarie ed alterazioni della moneta di conto in Italia nei secoli XVI-XVIII”, en Giuseppe Felloni, Scritti di storia economica, Genova, Società Ligure di Storia Patria, 1999, vol. I; 471-496.

Felloni, Giuseppe, Gli investimenti finanziari genovesi in Europa tra il Seicento e la Restaurazione, Milano, Giuffrè, 1971. 
García Guerra, Elena María, “Carlo V e il sistema finanziario milanese. 2. La coniazione delle monete”, en Marcello Fantoni (coord.), Carlo V e l'Italia, Roma, Bulzoni, 2000; 245-255.

Gelderblom, Oscar y Jonker, Joost, “Completing a Financial Revolution: the finance of the Dutch East India Trade and the Rise of the Amsterdam Capital Market, 15951612”, The Journal of Economic History, 64/3 (Cambridge, 2004): 641-672.

Giannini, Massimo Carlo, “Un caso di stabilità politica nella monarchia asburgica: comunità locali, finanza pubblica e clero nello Stato di Milano durante la prima metà del Seicento”, en Francisco Javier Guillamón Álvarez y José Javier Ruiz Ibáñez (coords.), Lo conflictivo y lo consensual en Castilla. Sociedad y poder politíco 1521-1715, Murcia, Universidad de Murcia, 2001; 99-162.

't Hart, Marjolein, Money and trust. Amsterdam moneylenders and the rise of the modern state, 1478-1794 [en línea], trabajo presentado al XIV ${ }^{\text {th }}$ International Economic History Congress, Helsinki, 25 de agosto de 2006. Disponibile en: http://www. helsinki.fi/iehc2006/papers1/Hart13.pdf [consultado el 26 se mayo de 2012].

Maffi, Davide, La cittadella in armi. Esercito, società e finanza nella Lombardia di Carlo II, 1660-1700, Milano, FrancoAngeli, 2010.

Moioli, Angelo, "The Changing Role of the Guilds in the Reorganization of the Milanese Economy throughout the Sixteenth and the Eighteenth Centuries”, en Alberto Guenzi, Paola Massa, Angelo Moioli y Fausto Piola Caselli (coords), Guilds, Markets and Work Regulations in Italy, $16^{\text {th }}-19^{\text {th }}$ Centuries, Aldershot, Ashgate, 1998; 32-55.

Murphy, Anne Louise, The Origins of English Financial Markets. Investment and Speculation before the South Sea Bubble, Cambridge, Cambridge University Press, 2009.

Muto, Giovanni, “Il governo della Hacienda nella Lombardia spagnola”, en: Paolo Pissavino y Gianvittorio Signorotto (coords.), Lombardia borromaica Lombardia spagnola 1554-1659, Roma, Bulzoni, 1995, vol. I; 265-302.

Muto, Giovanni, “The Spanish System: Centre and Periphery”, en Richard Bonney (coord.), Economic Systems and State Finance, Oxford, Oxford University Press, 1995; 231-259.

Pezzolo, Luciano, "Elogio della rendita. Sul debito pubblico degli Stati italiani nel Cinque e Seicento”, Rivista di storia economica, XII/3 (Bolonia, 1995): 284-330.

Pezzolo, Luciano, "Government Debt and Trust. French Kings and Roman Popes as Borrowers, 1520-1660”, Rivista di storia economica, XV/3 (Bolonia, 1999): 233261.

Pezzolo, Luciano, Una finanza d'ancien régime. La Repubblica veneta tra XV e XVIII secolo, Napoli, ESI, 2006.

Prodi, Paolo, “Operazioni finanziarie presso la corte romana di un uomo d’affari milanese nel 1562-63”, Rivista storica italiana, LXXIII/3 (Nápoles, 1961): 641-659. 
Pugliese, Salvatore, Condizioni economiche e finanziarie della Lombardia nella prima metà del secolo XVIII, Torino, Bocca, 1924.

Sabatini, Gaetano, Proprietà e proprietari a L’Aquila e nel contado. Le rilevazioni catastali in età spagnola, Napoli, Edizioni Scientifiche Italiane,1995.

Sella, Domenico, L'economia lombarda durante la dominazione spagnola, Bologna, Il Mulino, 1982.

Signorotto, Gianvittorio, "Stabilità politica e trame antispagnole nella Milano del Seicento”, en Yves-Marie Bercé y Elena Fasano Guarini (coords.), Complots et conjurations dans l'Europe moderne, Roma, École française de Rome, 1996; 721-745.

Tabarrini, Marco (coord.), "Relatione inedita dello Stato di Milano di G.B. Guarini”, Archivio Storico Italiano, V/1 (Florencia, 1867): 3-34.

Terreni, Andrea, “'Sogliono tutti i forastieri, i quali vanno a negotiare nelle città d'altri Dominii, essere favoriti et privilegiati'. La concessione della 'civilitas mediolanensis’ ai mercanti-banchieri genovesi nel XVI secolo”, en Carlo Donati (coord.), Alle frontiere della Lombardia. Politica, guerra e religione nell'età moderna, Milano, FrancoAngeli, 2006; 105-122.

Tracy, James, A Financial Revolution in the Habsburg Netherlands. Renten and Renteniers in the County of Holland, 1515-1565, Berkeley, University of California, 1985.

Vigo, Giovanni, "Manovre monetarie e crisi economica nello Stato di Milano (16191622)”, Studi storici, XVII/4 (Nápoles, 1976): 101-126.

Vigo, Giovanni, Fisco e società nella Lombardia del Cinquecento, Bologna, Il Mulino, 1979.

Recibido: 21-11-2010

Aceptado: 01-07-2011 